\title{
Deep Brain Stimulation and the Search for Identity
}

\author{
Karsten Witt • Jens Kuhn • Lars Timmermann • \\ Mateusz Zurowski $\cdot$ Christiane Woopen
}

Received: 5 May 2010 /Accepted: 25 January 2011 /Published online: 16 February 2011

(C) The Author(s) 2011. This article is published with open access at Springerlink.com

\begin{abstract}
Ethical evaluation of deep brain stimulation as a treatment for Parkinson's disease is complicated by results that can be described as involving changes in the patient's identity. The risk of becoming another person following surgery is alarming for patients, caregivers and clinicians alike. It is one of the most urgent conceptual and ethical problems facing deep brain stimulation in Parkinson's disease at this time. In our paper we take issue with this problem on two accounts. First, we elucidate what is meant by "beco ming another person" from a conceptual point of view. After critically discussing two broad approaches we
\end{abstract}

\footnotetext{
K. Witt $(\bowtie) \cdot$ C. Woopen

Institute for the History of Medicine and Medical Ethics,

Research Unit Ethics, University of Cologne,

Herderstraße 54,

50931 Cologne, Germany

e-mail: karsten.witt@uk-koeln.de
}

\section{J. Kuhn}

Department of Psychiatry and Psychotherapy,

University of Cologne,

Kerpener Strasse 62,

50937 Cologne, Germany

\section{Timmermann}

Department of Neurology, University of Cologne, Joseph-Stelzmann-Str. 9,

50924 Cologne, Germany

\section{Zurowski}

Neuropsychiatric Clinic, Toronto Western Hospital, Department of Psychiatry, University Health Network, Toronto, ON M5T 2S8, Canada concentrate on the notion of "individual identity" which centers on the idea of "core attitudes". Subsequently we discuss several approaches to determine what distinguishes core attitudes from those that are more peripheral. We argue for a "foundational-function model" highlighting the importance of specific dependency relations between these attitudes. Our second aim is to comment on the possibility to empirically measure changes in individual identity and argue that many of the instruments now commonly used in selecting and monitoring DBS-patients are inappropriate for this purpose. Future research in this area is advised combining a conceptual and an empirical approach as a basis of sound ethical appraisal.

Keywords Neuroethics · Deep brain stimulation . Personal identity · Parkinson's disease $\cdot$ Personality measurement

\section{Introduction}

Deep brain stimulation (DBS) has proven to be an effective therapeutic option in movement disorders such as Parkinson's disease (PD) [1]. Recently, it also has had a renaissance in psychiatric diseases: published data indicate that DBS can be applied successfully to significantly alleviate symptoms of several psychiatric disorders ([2, 3]). In spite of this good news the ethical legitimacy of DBS has been questioned in both public and academic settings $([4,5])$. Skeptics in both circles 
think that DBS is not as unproblematic as is sometimes supposed. They argue that its drawbacks are generally misconceived or at least underestimated. In this endeavor, they emphasize certain psychological changes in the patient.

Currently, the most commonly performed DBS surgery is the stimulation of the subthalamic nucleus (STN) to alleviate motor symptoms of Parkinson's disease. Therefore we will position the majority of our arguments on information and experience developed in the treatment of patients with this illness. Stimulation of the STN in PD patients has undoubtedly beneficial effects on motor symptoms and patients' quality of life [1]. Neuropsychiatric changes have at first glance not been very pronounced, and were not described in the first reports [6]. More recent large controlled trials investigating neuropsychiatric and neuropsychological changes in PD patients with DBS report small changes in executive functions like verbal fluency and an improvement in anxiety measures [7]. These results contrast with the experience and with more sporadic case reports of stimulation induced acute depression [8], hypomania and mirthful laughter $([9,10])$ as well as pathological crying [11]. There are also reports of patients suffering significant problems in social adjustment including marital problems and problems in professional life $([12,13])$. Consequently, there is a contrast between almost minimal neuropsychiatric changes reported by large trials using standardized tests and case reports as well as clinical experiences of sometimes more poorly defined and perhaps more difficultly quantified changes experienced by PD patients following the procedure.

Taking into account the tight anatomical and functional interconnection of limbic "emotional" loops, cognitive-associative loops and motor loops [14] in the basal ganglia, we speculate that the stimulation of these areas, including the STN can cause discrete changes in a wide spectrum of functions and may in fact account for some of those more sporadic reports mentioned above [15]. Changes of this type have already started to appear in the literature with investigators finding changes in PD patients' decision making abilities in response to medications [16] and DBS [17]. These reports highlight the complexity of PD patients' lives and the fact that the amelioration of motor symptoms may be just one aspect of their daily struggle. Taken together, today we can clearly show the highly beneficial effects of DBS on PD motor symptoms, but have to consider the existence of discrete, but possibly highly relevant changes in the stimulationinduced neuropsychiatric profile and social adaptation of PD patients following DBS.

Changes reported by these sporadic and sometimes nonspecific reports have led to some interesting skeptical arguments regarding DBS. These arguments focus on what philosophers call "the identity of persons" or, briefly, "personal identity". For example, there are anecdotal reports in the medical literature as well as in patients' internet chatrooms that you get 'another person' with stimulation. The question of whether there is such a change-of whether the patient under stimulation is not the same person as the patient without stimulation-obviously depends on the underlying concept of "personal identity". As most contributors to the above mentioned discussions feel that 'getting another person' is potentially problematic, their reports suggest a possible link between the conceptual question of what is meant by "personal identity" and the ethical challenge of weighing probably conflicting goods in the ethical evaluation of DBS.

Similar arguments as in internet chatrooms and in anecdotal reports occur in ethical discussions. In her recent article "Neuroethics for a new millennium" Adina Roskies asks:

"Some current interventions (...) will be such as to perhaps improve the health and functioning of the patient, but perhaps at the expense of altering the brain chemically or mechanically. Will certain (...) therapies change who we are? (...) Will we have to weigh the costs of biological death against continued life but destruction of ourselves?" ([18], 22, our emphasis)

Not quite as dramatic as Roskies but similar in purpose, Walter Glannon states with regard to a patient with advanced PD, whose motor symptoms were well controlled under stimulation but who developed symptoms including mania and chaotic behavior and therefore had to be kept in a closed ward:

"[I]n deciding whether to continue stimulating the brain for advanced PD [Parkinson's disease] (...) $[\mathrm{t}]$ he tradeoff is between acceptable quality of life regarding motor control and alteration of the mind." ([19], 291, our emphasis) 
The italicized passages in these quotations reveal a shared presupposition: both authors maintain that DBS may change the patient's identity. We call this empirical assumption the "Change-of-Identity Thesis" (CIT). The CIT figures prominently in the current debate on the ethical implications of DBS (cf. e.g. [4, 20-22]). It commonly goes along with the second, normative premise, that changing the patient's identity is ethically problematic and thus has to be weighed against the benefits of DBS. Although the second premise has to be sharpened in several respects ([21, 23]) these two theses form the basis for much of the ethical concerns surrounding DBS.

This may explain why currently there is a proliferation of interdisciplinary research projects dealing with problems of personal identity in DBS. This research faces not only empirical and ethical challenges, but also a conceptual one: In order to decide whether a change in mood, cognitive function, behavioral or affective aspects is a change in personal identity, we first have to clarify the concept of "personal identity". The empirical challenge then is to find out if in fact DBS causes changes in the patient's identity and how this can be measured. Assessing if changes are ethically relevant, which characteristics a change has to show in order to be seen as meaningful, and how different changes are to be weighed against each other becomes an ethical question. Thus, when we try to measure or to evaluate changes in the patient's identity we already presuppose an answer to the conceptual challenge, i.e. we already presuppose a sufficiently clear definition of "the patient's identity". In other words a solution to the conceptual challenge is indispensable for approaching the first two challenges. Its importance is increased by the fact that most research projects in this area involve participants from different disciplines. In such groups scientific progress depends to a large degree on a clear, commonly accepted terminology. Without answering the conceptual challenge this common terminology is missing.

Notwithstanding its significance for dealing with the empirical and the ethical challenge, the conceptual challenge has been somewhat neglected in discussing the consequences of DBS. Therefore, the primary aim of our paper is to work towards a solution of the conceptual challenge. This shall require an explication of what we mean when judging that someone has become "another person" or that DBS "alters the patient's identity". Our second aim is to reflect on the possibility of empirically measuring alterations in a patient's identity with the instruments now commonly used and possibly identify others that may be more helpful in selecting and monitoring patient progress following the procedure. If identity changes matter ethically, it should be in our interest to learn more about them.

\section{A Puzzling Case}

We will begin our discussion with a few quotes from a case reported by Schüpbach et al. [13]. It will give us an impression of what proponents of the CIT presumably have in mind when ascertaining "alterations in the patient's identity". The case describes a 38-year old female journalist, married with one child, who had PD (caused by a mutation in the parkin gene) for 30 years. The authors explain

"[b]efore stimulation, in spite of her motor handicap, she was dynamic: «Combating the disease gave meaning to my life. I hope that stimulation will allow me to get on with my life and my projects.» Six months after the operation, the patient was not satisfied in spite of a $75 \%$ improvement of her motor handicap ... After 18 months of stimulation, she was no longer able to work, had a loss of inspiration and a taste for her work and for life in general. «Now I feel like a machine, I've lost my passion. I don't recognize myself anymore.» Her family no longer interested her, she was easily exhausted, and had a loss of vitality ..., which led her to interrupt all professional activity." ([13], 1812, our emphasis)

The female journalist has significant worries concerning her identity following the operation. ${ }^{1}$ These worries were not epistemically grounded. When complaining "I don't recognize myself anymore", she does not appear to be saying that her memory or other cognitive faculties have been impaired. 'Her sight wasn't blinded', one could say.

\footnotetext{
${ }^{1}$ Similar worries were experienced by many of the other patients included in Schüpbach's study. Feelings of "unfamiliarity with themselves after surgery" (ibd: 1813) were reported by 19 out of 29 patients (ibd.).
} 
It seems that she doesn't recognize herself because in some important sense she is not herself anymore.

Still, such a statement is puzzling. When judging " $\mathrm{I}$ am not myself anymore", the woman seems to be saying that she is and, at the same time, is not the same individual as before the operation. But this would be an overt contradiction. No single thing can at the same time be itself and not be itself. How can we avoid this impasse?

A possible way out is to acknowledge "the multifarious nature of personal identity" ([24], 3): that there is not a single, monolithic question of personal identity but several interrelated questions. One way to examine this issue is to take up Marya Schechtman's influential distinction between the "characterization question" and the "reidentification question" of personal identity (ibd. 1). ${ }^{2}$ The characterization question asks about personal identity in the "Who am I?" sense. It refers to what is at issue in identity crises and is somehow closely linked to our deepest values and beliefs which "make someone the person she is" (2). It thus involves certain elements or states figuring prominently in a person's mental life. Following Olson ([36], 356) we will call the kind of identity asked for in the characterization question "individual identity". Some writers use the term "personality" instead of "individual identity" when answering the characterization question (e.g. [4, 37]). We prefer to keep these notions apart, using "personality" as a psychological concept and "individual identity" as a philosophical concept.

The reidentification question asks for numerical identity. More formally, it asks if "a person who exists at one time is identical with something that exists at another time (whether or not it is a person then)" ([36], 357). "Numerical identity" denotes the logical relation of identity. It concerns identity in a deep metaphysical sense.

It is impossible for anything to change its numerical identity. Thus, while the female journalist's individual identity seems to have changed, her numerical identity must have been unaffected by DBS if the above description is to make sense. In other words, while she may have changed her

\footnotetext{
${ }^{2}$ A similar distinction is made by many philosophers working on personal identity; cf. e.g. [25-27] and [28]. Not all philosophers agree that this move is correct; cf. [29-34]; the same is implicit in [35], 204-209, 298-302.
}

individual identity, in a deep metaphysical sense she must have remained one and the same human being.

In our essay we are exclusively concerned with individual identity. Questions relating to numerical identity will stay out of focus.

\section{Individual Identity}

\section{Two Broad Views}

What does it take to remain the same person? In answering this question, some people are quite radical. Simon Blackburn remarks that Proust's pervasive melancholy can partly be attributed to his belief that we constantly change. This is due to his conviction

\section{"that the self that achieves a desire is never the same as the self that had the desire." ([30], 259, n.35)}

But such an extreme view is not only apt to induce melancholy; it is plainly wrong. If Proust were correct we all would change our identities several times a day: before and after breakfast or every time we quench our thirst or scratch our heads. But, clearly, this conflicts with our intuitions about what it means to remain the same person. If Proust really believed this, his reasoning must have somewhere gone awry.

A similarly broad concept of "identity" has recently been put forward by Synofzik and Schläpfer [23]. The authors begin their discussion of what they interchangeably call "personality" or "self" with the statement that apparently,

"the question whether DBS ... might alter personality or not seems to be one of the fundamental ethical questions." ([23], 2) ${ }^{3}$

This sounds as if Synofzik and Schläpfer side with us in analyzing the validity of objections against DBS resting upon CIT, seemingly using the terms "persona

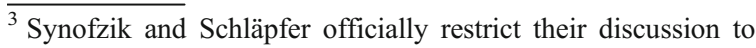
psychiatric indications. An important reason for this restriction seems to be their goal to emphasize the absurdity of the claim that every change in what they call "personality" is bad. This is an important point for evaluating the ethical controversy surrounding the CIT. We see no reason why their conception of "personality" should apply only to psychiatric patients. In fact, the authors themselves refer to 'personality'-relevant consequences of DBS for movement disorders; cf. [23], 4.
} 
lity" and "self" as equivalent to what we call "individual identity". But surprisingly they hold that:

"[t]o gain normative orientation, the concept of «personality» is not useful-even if a naturalistic notion is employed." (1)

How do they justify this antinormative claim? The answer to this question will prove important for our own thoughts. It is therefore best developed in stages.

Synofzik and Schläpfer begin their discussion of the topic by pointing out the prima facie importance of defining what is meant by "personality/self" in order to "delineate normative questions from the fact whether DBS «changes personality or not»" (2). They then go on to dismiss the notion of a "non-physical self" which they deem unhelpful and "highly implausible" and which in their view should be replaced by some "naturalistic account of the self" (3). The next step is to explicate their own account of "personality" which is the crucial step in their argument. In their view "personality" denotes "a supramodal representational system with largely heterogeneous functional and (self-)representational levels" (4). This supramodal system includes "low-level sensory, motor or vegetative states" as well as "highly elaborated mental phenomena such as the experience of agency" (ibd.). In other words, what they propose is a conception of "personality" that embraces practically all biological and mental phenomena occurring in a human being. With such a notion in mind, the above-mentioned, antinormative conclusion easily follows: If the alteration of even "low-level sensory, motor or vegetative states" entails an alteration of our personality, it is evident that this concept (alone) cannot serve as a moral compass.

Synofzik and Schläpfer's understanding of "the self" (3) is doubtful for reasons having to do with our refutation of Blackburn's presentation of the Proustian view. It also becomes clear that the supposed equivalence between "personality/self" and "individual iden tity" no longer holds because according to Synofzik und Schläpfer, "personality" is an inherently transient phenomenon. "Personality" as explicated by the

\footnotetext{
${ }^{4}$ Perhaps Synofzik and Schläpfer do not intend their account of "personality" to answer the characterization question (there is some reason to believe this; cf. the following note) - but then their antinormative claim reduces to a mere terminological point.
}

supramodal-system approach is therefore not suited to serve our purpose of characterizing a person. An adequate conception of "individual identity" has to shed light on the CIT and to serve as a conceptual background for the controversy surrounding much of the ethical discussion about DBS. The CIT is concerned with questions of remaining or not remaining the same person - questions which the supramodalsystem model cannot answer. Therefore, whatever merits this approach may have in other regards, it is unhelpful for discussing questions concerning cases like the one of the female journalist in a meaningful and differentiating way. In order to make progress on this point we have to go beyond this and other similarly broad notions of personal identity. ${ }^{5}$

\section{Core-Periphery Models}

If not every change in a person's psyche counts as a change in identity, then which changes do? It is quite common in philosophy to think about a person's individual identity in terms of a core-periphery model, the core-periphery distinction being introduced to indicate that not all psychic elements are of equal importance to the person ([31], 99-100; [32], 153$154 ;[33,34], 27-28)$. To say that psychic element $\mathrm{E}$ is 'located' closer to the core than another element $\mathrm{F}$ means that $\mathrm{E}$ is more important for and more distinctive of the person than $\mathrm{F}$ :

"[The] core attitudes ... determine what [a person's] life is all about and what is important to her; they give shape and contour to her way of looking at, and being in, the world. In a very significant sense, they make her who she is." ([31], 100)

All changes and only changes in central attitudes constitute a change in individual identity, i.e. if and only if our central beliefs, values, ideals, plans, projects, ideologies etc. change, we change in a substantial way. That much is granted by many

\footnotetext{
${ }^{5}$ It should be added that at the end of their presentation Synofzik and Schläpfer suggest how mental elements crucial for individual identity might be characterized: "[T]he ethically important question is not whether DBS alters personality or not, but whether it does so in «a good or bad way» from the patient's very own perspective." (4) This comes close to what we call the "activity model of individual identity". This model will be discussed in the next section.
} 
philosophers working in the field. ${ }^{6}$ There is, however, some disagreement over the question what it means to say that certain attitudes are "central" or "belong to the core". This question will be addressed in the next two subsections.

\section{The Activity Model}

According to a widely influential account, a given attitude's being central to a person's identity necessarily involves that person's reflective endorsement. ${ }^{7}$ The person has to somehow support or identify with an attitude (a belief or a desire) of hers in order that it may be central to who she is. As an example, consider Sheila, a young woman living in New York City. Sheila cares a lot about her grandmother which is why she regularly visits her in the nearby nursing home. Usually she doesn't deliberate over these visits but today she feels an intense reluctance to go and see the old lady. Being surprised by her dislike, Sheila asks herself if she really wants to keep on with her habit. On reflection, however, she endorses her visiting desire and rejects the other: she wants her visiting desire to be effective in action. Her desire to meet her grandmother is thus part of Sheila's individual identity whereas the desire to abandon the visit is not.

Does her endorsement establish the visiting desire's being central to Sheila's identity? Not necessarily. Sheila may have many other desires, each of which she would endorse on reflection and some of which may conflict due to changing circumstances. Let's assume that her desire to get on with her career is one such desire. One day, she receives an interesting job offer from the west coast. To accept it would involve seeing her beloved grandma only a few times a year. This troubles Sheila and after some deliberation she decides to stay in New York City. From this, one can deduce that Sheila's visiting desire is more important to her than her desire to get ahead with her job. It seems that only if this result is (or would be) repeated in most cases of conflict between the visiting desire and other desires belonging to

\footnotetext{
$\overline{{ }^{6} \text { Cf. e.g. [27] }}$ 320. Perhaps this claim is too bold and we should include emotions into our analysis of individual identity; cf. [34]. This, however, is a task for another day.

${ }^{7}$ Cf. e.g. [38], 603-610; [39], 18; [33], 170-172. Probably we can also add Synofzik and Schläpfer, [23], to this list; cf.n. 5.
}

Sheila's individual identity that it can truly be said that the former desire is central to her identity. ${ }^{8}$

The notion of "centrality to identity" seems to involve acts of rejection, endorsement and ordering of attitudes. But what role do these acts play exactly? The well-known philosopher Harry G. Frankfurt writes:

"It is these acts of ordering and rejectionintegration and separation - that create a self out of the raw materials of inner life." ([33], 170)

This sounds as if without these acts of ordering and endorsement (or rejection) the inner life of the person is nothing but a disordered jumble of raw materials waiting for the person to impose upon them a neat core-periphery structure. Call this the "activity model" of individual identity. ${ }^{9}$ As Sheila's example shows, this model seems fit to explain what "centrality to identity" is supposed to mean.

However, the activity model of individual identity shows an explanatory gap in leaving open the question of who is supposed to carry out the 'acts of ordering and endorsement' mentioned above. One might regret that "creating an orderly arrangement" ([33], 173) among the objects in a room as well as within oneself is an activity which presupposes an agent. But cleaning up does not simply happen-it requires someone who does it.

One way to complete Frankfurt's picture is to think of the agent as somehow distinct from the rest of the raw materials of inner life. In whatever state of disorder those may find themselves, the agent "as distinct from relevant psychological events, processes and states" ([42], 39) enters the scene and puts them in order. This is an interpretation that we would like

\footnotetext{
${ }^{8}$ Probably, hypothetical endorsement would suffice here. In what follows, we will not discuss this issue further for the sake of simplicity.

${ }^{9}$ As Frankfurt is mostly concerned about questions of authenticity and autonomy, we might also interpret his remarks as indicating that the above mentioned acts create something which may be called "our own identity" and which may be contrasted with, e.g., an "alienated identity". In this case Frankfurt would probably escape our criticism. But even if we take him literally here we should add that in later publications Frankfurt himself casts doubt on the activity model and tries to formulate a model of individual identity involving so-called "volitional necessities" which comes close to our own proposal; cf. e.g. [40] and [41]. However it is a matter of controversy how successful he has been in this respect; cf. 48, 93-94.
} 
to avoid. ${ }^{10}$ When writing that "someone" is required to do the ordering and rejecting, we don't want to introduce into our model a mystical agent "floating around or somehow attached to the human being" ([32], 153).

Instead we take another route to close the explanatory gap left open by the activity model of individual identity. In this we follow the lead of such diverse authors as Sigmund Freud, Simon Blackburn, Michael E. Bratman and many others who think that the vantage point from which the acts of endorsement and ordering can be carried out is constituted by other desires. These, of course, are not just any desires. Instead,

"[ $t]$ hose desires have to do with the conception I have of the life I want and the sort of person I want to be." ([25], 130)

If this is right, the activity model is unpersuasive. Remember that according to that model the self is created through certain acts out of the raw materials of inner life. Before these acts have taken place, there are desires and beliefs but there is also a lack of structure. Certainly, a structureless set of attitudes cannot account for such a cognitively and volitionally sophisticated phenomenon as a conception of the life a person wants to lead and the sort of person she wants to be. Without something like a more or less elaborated core-periphery structure of desires and beliefs already in place, she lacks the vantage point from which to carry out the acts of ordering and endorsement. In an important aspect the picture upon which the activity model is based is therefore inappropriate. Our selves do not arise like a phoenix from the ashes.

These considerations are not without consequences for the general thrust of activity-based models of centrality to individual identity. We have just argued that the acts of endorsement, ordering and rejection presuppose an already structured inner life. But this means that these acts just cannot be a necessary constituent of centrality to identity. The present account has taken us full circle: according to it, a desire is central to a person's identity only if it is endorsed by a desire which is central to that person's identity. It is obvious that such an account doesn't

\footnotetext{
${ }^{10}$ For criticism of such 'homuncular' conceptions of the agent or the 'self', cf. e.g. [43], 23; [25], 124-126; [42], 38-39; [32], $152-153$.
}

give us any additional information except for the well-established fact that some desires (and beliefs) are more important than others for a given person. ${ }^{11}$

\section{The Foundational-Function Model}

The previous discussion has shown that acts of rejection, endorsement and ordering are not necessary for a mental element to belong to the core of a person's identity. Centrality to identity, it seems, does not depend on any activity on behalf of the subject. It may (totally or in part) be established by certain acts of the subject herself but it might as well (totally or in part) be shaped by education, socialization and all kinds of manipulation (cf. [31], 99-105) - or, as it is assumed in the Change-of-Identity Thesis (CIT), by DBS. In the latter cases the subject is (more or less) passive; (to some degree or other) she 'receives' her identity, including an appropriately structured set of core attitudes.

On the face of it, this may sound repugnant: how can anything as meaningful as the difference between the attitudes belonging to the core and those belonging to the periphery of our identity be the product of external intervention? Surely, what distinguishes that in which we believe most deeply and which we most care about from the rest of our attitudes must besomehow-grounded in us, i.e. it must be-at least partly - the product of our own doing. From this kind of reasoning it is seems to be just a short step to the activity model. How can we avoid relapsing? Two considerations might prove helpful. First, our everyday experience suggests practicing some humility. We cannot control everything in our lives. A lot of things that are crucial for who we are and what we do are simply given to us (including our biological make-

\footnotetext{
${ }^{11}$ If this argument is correct it is an objection not only to Frankfurt's model but to any conception of individual identity which presupposes activity on behalf of the subject. This especially concerns some so-called "narrative theories of individual identity" holding that a person creates his identity by forming an autobiographical narrative. These theories are currently very popular in the bioethics literature, cf. [21, 28, 44] and [19]. One way for narrativists to avoid our critique may be to emphasize the social nature of individual identity figuring prominently in their accounts, cf. [24, 45, 46]. They could try to argue that a person's individual identity preceding the identity created by her first autobiographical narrative is somehow constituted by a biographical story, suitably told by others. It is beyond doubt that these points deserve much more discussion than we can give them here.
} 
up). We discover ourselves at least as much as we create ourselves. Second, in the foregoing paragraph we qualified our assertions by adding in parentheses that activity and passivity concerning the structure of individual identity may both play their part. In fact, this is probably the case in most adults. In most of us at least some of our core attitudes have earned their place through acts of endorsement and ordering. The point we would like to emphasize is that it just doesn't have to be this way-or else the whole picture is threatened by incoherence.

Now, if acts of ordering and endorsement cannot ground centrality to identity, what else can? In our view "centrality to identity" should be analyzed in terms of certain relational properties of the relevant attitudes, regardless of their origin. A relational property that is prominent in some accounts of the core of individual identity is the coherence between mental elements:

“[W]e take an agent's true or most central self

to be a subset of these acceptances and preferences, namely, those that cohere together." $([38], 608)^{12}$

What make the elements of a given set cohere is that they "fit together" (ibd.). ${ }^{13}$ Undoubtedly, coherence is important for the idea of "individual identity" but it should not be overvalued especially since this relation can hold between central as well as between central and peripheral attitudes. Remember Sheila. One of the things she most cares about is the well-being of her grandma. This central desire may well 'fit together' with her desire to buy a bunch of roses for the old lady. But to deduce from this that the latter desire is also central to Sheila's identity seems plainly wrong. The desire may, for example, be perfectly ephemeral; perhaps it occurred just because only today she took a different route to the nursing home passing a flower shop. Coherence thus cannot (fully) explain how it is that some elements in a person's psyche are closer to the core than others. ${ }^{14}$

\footnotetext{
$\overline{12 \text { Cf. also [25] }}, 123$; [41], 139; [33], 172-174.

${ }^{13}$ In most cases, conflicts between mental elements that are due to changing circumstances do not threaten coherence. For similar considerations concerning "wholeheartedness", cf. [47], 103.

${ }^{14}$ It may, however, be a necessary condition for centrality to identity in that only cohering attitudes can be a part of the person's identity. This is disputed, cf. [48].
}

A relational property which is better suited for our purposes is the foundational function of core attitudes (cf. [27], 320). What do we mean by "foundational function"? Consider an analogy from architecture. In a building we can distinguish load-bearing walls from those walls that have no support function. The latter can be removed and rebuilt at will without endange ring the stability of the building. This is not true for load-bearing walls. To remove them causes the building to cave in. Its support function is not only a good way to find out if a given wall is a loadbearing one or not; by definition load-bearing walls carry the weight of the building. The same goes for core attitudes. ${ }^{15}$ They serve as the foundation for many or most of our other attitudes. Noggle writes:

“A person's core beliefs and commitments are the foundation for the rest of her cognitive structure, the lens through which she sees the rest of the world. (...) A change in them constitutes a profound paradigm shift $-\mathrm{a}$ conversion of sorts - that produces a radical cognitive discontinuity between the pre- and postchange selves. (...) A similar picture can be drawn for human motivation." ([27], 319)

If a person's core attitudes change, she changes. This model of individual identity draws on the assumption that our beliefs and desires (broadly understood) are not all on a par. Most of them are connected via dependency relations such that the validity of a more 'subordinate' attitude depends on the validity of a 'superior' one but not vice versa. These structures can be characterized as hierarchies of desire and of belief. In the realm of desires, these hierarchies may be expressed by way of the distinction between 'instrumental' and 'intrinsic' desires that goes back at least to Aristotle (cf. [49], 113-114). In the realm of beliefs such structures are less obvious, but they are still in place (cf. [25], 154-163). Changes in certain beliefs entail changes in countless other beliefs while changes in others do not have many further consequences. Just compare someone who had the passing thought that it is windy outside and now comes to believe that it isn't, with someone who used to firmly believe in god and now finds out (for

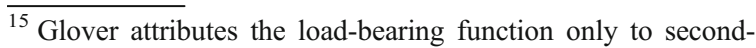
order beliefs, which he calls "structural beliefs"; cf. [25], 156. We are more permissive at this point.
} 
himself) that there is no god out there. Our most important beliefs can plausibly be regarded as (nearly) fixed points in our belief-system; the other beliefs being (regularly) adjusted to them or given up (cf. [25], 155-156). ${ }^{16}$

If we interpret "centrality to identity" in terms of "foundational function", it becomes clear why a change in her central attitudes changes the person. A change in one of her core attitudes resounds through the chain(s) of more peripheral attitudes that depend on them. It entails what Noggle calls "a profound paradigm shift" in her cognitive or practical stance to the world. ${ }^{17}$ The reverse is not true. As her core attitudes do not depend on her peripheral attitudes, the latter can be given up without this having any direct consequences for the person she is. Return once more to Sheila. Assume she has just learned that her grandmother doesn't like flowers. To give up her prior desire to buy a bunch of roses does not change her in any interesting sense. On the contrary, it is by quitting her desire to buy flowers that she readjusts her 'volitional periphery' to her central desire to care for the well-being of her grandmother, thus underlining the importance of the latter desire.

In our view this approach helps to explain what we mean when we say that some attitudes "belong to the core" or "are central to the identity of" a given person. Unlike accounts that rely on acts of rejection, endorsement and ordering, it does not presuppose what it intends to explain. Unlike broad views or accounts of centrality operating solely with a coherence-criterion, it can differentiate between central and peripheral attitudes. Thus, if we want to be able to evaluate the CIT or to understand complaints like the one of the female journalist, we should look to a notion of "centrality to identity" which takes into account the foundational function of attitudes.

\footnotetext{
$\overline{{ }^{16} \text { Dependency }}$ relations can also exist between attitudes of a different order. We form higher-order attitudes when we reflect upon and then endorse or reject certain first-order attitudes. Noggle writes that higher-order desires "are best seen as getting their content from core desires" ([27], 320). This would, by the way, explain why higher-order desires are commonly regarded as being more authentic - thus connecting the present essay with the current preoccupation with 'authenticity' in some parts of ethics and bioethics, cf. [50, 51].

${ }^{17}$ If coherence is a necessary condition for centrality to identity (cf. n.14) the effects of a change in a core attitude may even be more sweeping because in order to reestablish coherence the remaining core attitudes may to be adjusted to the change.
}

\section{The Measurability Question}

Having outlined the conceptual framework we want to finish our investigation of the conceptual challenge with some observations on the measurability of individual identity in the DBS context. The question is whether changes in individual identity as conceptualized above can be ascertained by the tests now commonly used in selecting and monitoring DBS patients. With this in mind we now turn from philosophy to more empirical matters.

In empirical research the concept coming closest to what we have been examining throughout this paper is the notion of "personality" as used in psychology and psychiatry. Due to a definition widely acknow ledged in the respective disciplines, "personality" refers to

"the organized set of characteristics possessed by a person that uniquely influences his or her cognitions, motivations, and behaviors in various situations." ([52], 5)

This set of characteristics is commonly regarded as remaining fairly stable at least in the medium term (cf. [53], 5).

So far, tests of neuropsychological as well as neuropsychiatric alterations in the large controlled trials of DBS mentioned at the beginning of this article were clinically driven, lacking a full-blown background conception of "personality". Additio nally a review of 30 studies examining cognitive effects of DBS in PD revealed that only 2 of them had the statistical power to detect large effects, whereas none of them could detect small or medium effects [54]. This may explain why reliable data of changes in personality have so far been sparse and why the applied test instruments may not adequately answer the question of whether or not these changes in fact occur. In order to make progress on this question, it might be expedient to have a closer look on what psychology and psychiatry have to offer to DBS/PD-research.

In psychiatry there are two general approaches that can in principle be used to ascertain changes in personality: the categorical and the dimensional approach. In what follows we will briefly introduce and evaluate them. 
The categorical approach is prominent in the Diagnostic and Statistical Manual of Mental Disorders (DSM-IV-TR). Its aim is to distinguish between normal and pathological forms of personality. The DSM-IV-TR lists ten personality disorders defined by approximately 7-9 items each, of which a subset must be present in order to meet the diagnostic threshold. In addition, the DSM-IV-TR includes a hierarchical system of three clusters of personality disorders, based on similarities in their characteristics: (1) odd/ eccentric, (2) dramatic/emotional/erratic, and (3) anxious/fearful. This categorical, hierarchical taxonomic system offers several pragmatic advantages: it maps out neatly the decision of whether to provide treatment, and it is relatively easy to use for purposes of communication and conceptualization. Much information can be conveyed using a single diagnostic label regarding features, associated conditions, and possible treatment options.

In DBS/PD-research test instruments based on the categorical approach such as the Structured Clinical Interview for DSM disorders (SCID-II) have occasionally been used [55]. However, we doubt that these instruments are adequate for our purpose: It is conceivable that the implantation and subsequent stimulation of neural tissues may cause some pathological changes in personality. With regard to the diagnostic criteria these would be best characterized as an "Organic Personality Disorder" (ICD-10: F07.0) ${ }^{18}$ or a "Personality Change Due to a General Medical Condition" (DSM-IV-TR). However, we are not aware of any evidence that changes following DBS are pronounced enough to cause a full-blown personality disorder in a significant number of cases. Of course, it cannot be ruled out a priori that DBS can have such severe consequences, but it seems at least highly improbable to us as far as evidence from studies, case reports and our own experience is concerned that this regularly is the case.

We rather presume that the changes mentioned will normally take place on a subclinical level. ${ }^{19}$ If this is

\footnotetext{
18 "ICD-10" is the abbreviation for "International Statistical Classification of Diseases and Related Health Problems". It is published by the World Health Organization.

${ }^{19}$ Since an Organic Personality Disorder is often accompanied by enduring emotional instability and reduced impulse control, we may pay more attention on symptoms which are associated typically with personality disorders within the second cluster (see above).
}

correct, tests based on the categorical approach to personality will (regularly) turn out to be too coarsegrained to register the kind of changes we are interested in-changes like the one experienced by Schüpbach's female journalist. What we need are instruments that are more sensitive than the categorical approach taken by the DSM-IV-TR. Perhaps the dimensional approach to "personality" can afford a sensible starting point to answer the measurability question.

The dimensional approach to "personality" is mainly associated with the Trait Theory that emerged toward the end of the 1980s. The Trait Theory is focused on identifying and measuring individual personality characteristics [56] along five dimensions. This five-factor model of personality represents five core traits or dimensions that form human personality $([57,58])$. While researchers often disagree about the exact labels for each dimension, the following are described most commonly: Extraversion, Agreeableness, Conscientiousness, Neuroticism and Openness. But which of the dimensional tests may be useful for our purposes?

The Dimensional Assessment of Personality Pathology_Basic Questionnaire (DAPP-BQ) [59] and the Temperament and Character Inventory (TCI) [60] are two empirically well established tests based on the dimensional approach. They were designed to assess personality disorders along the full continuum-from mild to extreme trait manifestations [61]. Their focus on personality disorder may render them, however, inappropriate to detect the subtle changes we are concerned about. Instruments such as the Revised NEO Personality Inventory (NEOPI-R) [62] or the NEO-Five Factor Inventory (NEOFFI) may be more useful in the longitudinal exploration of changes in personality dimensions of patients with DBS.

The NEO-PI-R and the NEO-FFI may indeed be fine-grained enough to ascertain changes in perso nality due to DBS. However, it is an open question if these tests are able to register the changes we have been concerned about throughout this paperchanges in individual identity. On the face of it, the concepts of "individual identity", understood accor ding to the foundational function model and "perso nality" in terms of the Trait Theory are not equivalent, because the Trait Theory of personality does not include information about the relation between central 
and peripheral attitudes. ${ }^{20}$ We hence presume that currently available and usually applied scales to detect personality changes in patients with DBS are not suitable to reliably ascertain the kinds of changes in personal identity that from an ethical point of view might turn out to be the most relevant and troubling in DBS.

Therefore we propose a design for longitudinal studies combining a philosophical investigation of the concept of "personal identity", semi-structured interviews of patients and their caregivers, and validated quantitative test instruments. We expect such a design to clarify the aspects and severity of identity changes that are ethically relevant for patients, caregivers and clinical staff in the context of DBS. Changes not detectable with standard instruments might be identified in the interview. This especially concerns the difficult question of centrality of certain beliefs, projects, etc. for the patient. The inclusion of caregivers might help to supplement the patient's own perspective with the information gathered in the interview with the caregiver. This may supply a potentially fruitful second account of how DBS has affected the patient's identity. ${ }^{21}$

\section{Conclusion and Future Perspectives}

Cases like Schüpbach's female journalist have given rise to a series of concerns about and even objections against DBS all of which feature the patient's identity. A common presupposition prominent in most of these objections is the "Change-of-Identity Thesis" (CIT). In order to better understand what is at stake in the CIT we tried to illuminate what a "change in a person's identity" means by discussing several possible models of "individual identity" including two

\footnotetext{
${ }^{20}$ Kristjánsson shares our view that the two notions diverge; $\mathrm{cf}$. 34, 26-27. However, he goes on to claim that the traits constituting individual identity are a subclass of a larger set of personality traits. We are not sure if there is a conceptual link between "individual identity" and "personality" in the way Kristjánsson is depicting and thus avoid such a commitment.

${ }^{21}$ Currently a study designed as proposed in the above paragraph, the ELSA-DBS study, is taking place in Cologne, Germany, and Toronto, Canada. "ELSA-DBS" is the abbreviation for "Ethical, Legal and Social Aspects of Deep Brain Stimulation"; for further information on ELSA-DBS cf. http:// geschichte-ethik.uk-koeln.de/forschungsstelle-ethik/forschung-1/ elsa-dbs.
}

broad views, the activity model and a model emphasizing the role of coherence. We finally opted for the "foundational-function model" that in our view has the best prospects to serve as a model for the changes in a patient's identity we are most concerned about in PD/DBS-research. We thus propose our approach as a suitable starting point for a differen tiated ethical evaluation of DBS.

Of course, our work isn't finished yet. It remains unclear if 'foundational function' can only be attributed to attitudes that do not depend on any other attitudes or if attitudes "crystallizing pressures from various elements of one's psychic stew" ([42], 51) can also exert this function. Furthermore the role of coherence in indivi dual identity has to be made more precise. We suggested that it might be a necessary feature of elements constituting individual identity but also pointed out that this is not devoid of controversy (see above, n. 14). Lastly, the foundational-function model itself has to be made more precise; we need to formulate some criterion, some necessary and/or sufficient conditions for an attitude to be a core attitude.

If changes in personality matter ethically we should strive to reliably identify them. Our proposed answers to the "measurability question" offer some possibilities for future empirical research that may capture salient aspects of personality change following DBS. It appears that the dimensional approach will be the one most likely to yield valuable results. However, this empirical endeavor should be accompanied by some in-depth thoughts on the relation between "personality" and "individual identity". Since there are at least prima facie differences between the two concepts, it is questionable if tests geared to the former can yield useful results about the latter. This underlines the importance of supplementing quantitative test instruments with data from semi-structured qualitative interviews of patients and caregivers focusing on individual identity and the possibility of developing further instruments that will bring us closer to understanding these important phenomena.

Acknowledgments We would like to thank the members of the ELSA-DBS Study Group (see above, n. 21) for lively discussion of some of the issues covered in this paper. Furthermore we thank the German Federal Ministry of Education and Research for financial support. Finally we thank Achim Lohmar, an anonymous reviewer from "Neuroethics", and the special issue editor for helpful comments on earlier drafts of this paper. 
Open Access This article is distributed under the terms of the Creative Commons Attribution Noncommercial License which permits any noncommercial use, distribution, and reproduction in any medium, provided the original author(s) and source are credited.

\section{References}

1. Deuschl, G., C. Schade-Brittinger, P. Krack, J. Volkmann, H. Schaefer, K. Boetzel, et al. 2006. A randomized trial of deep-brain stimulation for Parkinson's disease. The New England Journal of Medicine 355: 896-908.

2. Kuhn, J., W. Gaebel, J. Klosterkötter, and C. Woopen. 2009. Deep brain stimulation as a new therapeutic approach in therapy-resistant mental disorders: ethical aspects of investigational treatment. European Archives of Psychiatry and Clinical Neuroscience 259: 135-41.

3. Kuhn, J., T.O. Gründler, D. Lenartz, V. Sturm, J. Klosterkötter, and W. Huff. 2010. Deep brain stimulation for psychiatric disorders. Deutsches Ärzteblatt International 107: 105-13.

4. Merkel, R., G. Boer, J. Fegert, T. Galert, D. Hartmann, B. Nuttin, et al. 2007. Intervening in the Brain: Changing Psyche and Society. Berlin, Heidelberg: Springer.

5. Hildt, E. 2009. Der implantierte Mensch: Therapie und Enhancement im Gehirn. Alber: Freiburg i.Br.

6. Parkinson-Study-Group. 2001. Deep-brain stimulation of the subthalamic nucleus or the pars interna of the globus pallidus in Parkinson's disease. The New England Journal of Medicine 345: 956-63.

7. Witt, K., C. Daniels, J. Reiff, P. Krack, J. Volkmann, M.O. Pinsker, et al. 2008. Neuropsychological and psychiatric changes after deep brain stimulation for Parkinson's disease: a randomised, multicentre study. Lancet Neurology 7: 605-14.

8. Bejjani, B.P., P. Damier, I. Arnulf, L. Thivard, A.M. Bonnet, D. Dormont, et al. 1999. Transient acute depression induced by high-frequency deep-brain stimulation. The New England Journal of Medicine 340: 1476-80.

9. Herzog, J., J. Reiff, P. Krack, K. Witt, B. Schrader, D. Mueller, et al. 2003. Manic episode with psychotic symptoms induced by subthalamic nucleus stimulation in a patient with Parkinson's disease. Movement Disorders 18: 1382-4.

10. Krack, P., R. Kumar, C. Ardouin, P.L. Dowsey, J.M. McVicker, A.L. Benabid, et al. 2001. Mirthful laughter induced by subthalamic nucleus stimulation. Movement Disorders 16: 867-75.

11. Wojtecki, L., J. Nickel, L. Timmermann, M. Maarouf, M. Südmeyer, F. Schneider, et al. 2007. Pathological crying induced by deep brain stimulation. Movement Disorders 22: 1314-6.

12. Agid, Y., M. Schüpbach, M. Gargiulo, L. Mallet, J.L. Houeto, C. Béhar, et al. 2006. Neurosurgery in Parkinson's Disease: the doctor is happy the patient less so? Journal of Neural Transmission, Suppl. 70: 409-14.

13. Schüpbach, M., M. Gargiulo, M. L. Welter, L. Mallet, C. Béhar, and J. L. Houeto, et al. Neurosurgery in Parkinson disease: A distressed mind in a repaired body? Neurology. 2006: 1811-6.
14. Alexander, G.E., M.D. Crutcher, and M.R. DeLong. 1990. Basal ganglia-thalamocortical circuits: parallel substrates for motor, oculomotor, "prefrontal" and "limbic" functions. Progress in Brain Research 85: 119-46.

15. Mallet, L., M. Schüpbach, K. N'Diaye, P. Remy, E. Bardinet, V. Czernecki, et al. 2007. Stimulation of subterritories of the subthalamic nucleus reveals its role in the integration of the emotional and motor aspects of behavior. Proceedings of the National Academy of Sciences of the United States of America 104: 10661-6.

16. Euteneuer, F., F. Schaefer, R. Stuermer, W. Boucsein, L. Timmermann, M.T. Barbe, et al. 2009. Dissociation of decision-making under ambiguity and decision-making under risk in patients with Parkinson's disease: a neuropsychological and psychophysiological study. Neuropsychologia 47: 2882-90.

17. Frank, M.J. 2006. Hold your horses: a dynamic computational role for the subthalamic nucleus in decision making. Neural Networks 19: 1120-36.

18. Roskies, A. 2002. Neuroethics for the New Millenium. Neuron 35: 21-3.

19. Glannon, W. 2009. Stimulating brains, altering minds. Journal of Medical Ethics 35: 289-92.

20. Fuchs, T. 2006. Ethical issues in neuroscience. Current Opinion in Psychiatry 19: 600-7.

21. Focquaert, F., and D. DeRidder. 2009. Direct intervention in the brain: ethical issues concerning personal identity. Journal of Ethics in Mental Health 4: 1-7.

22. Lipsman, N., R. Zener, and M. Bernstein. 2009. Personal identity, enhancement and neurosurgery: a qualitative study in applied neuroethics. Bioethics 23: 375-83.

23. Synofzik, M., and T.E. Schlaepfer. 2008. Stimulating personality: Ethical criteria for deep brain stimulation in psychiatric patients and for enhancement purposes. Biotechnology Journal 3: 1-10.

24. Schechtman, M. 1996. The constitution of selves. Ithaca, London: Cornell University Press.

25. Glover, J. 1988. I: The philosophy and psychology of personal identity. London u.a.: Penguin.

26. Olson, E.T. 1999. The human animal: Personal identity without psychology. Oxford u.a.: Oxford University Press.

27. Noggle, R. 1999. Integrity, the self, and desire-based accounts of the good. Philosophical Studies 96: 303-31.

28. DeGrazia, D. 2005. Human identity and bioethics. Cambridge u.a.: Cambridge University Press.

29. Shoemaker, David. 2008. Personal identity and ethics. In Stanford encyclopedia of philosophy, ed. Edward N. Zalta.

30. Blackburn, S. 2000. Ruling passions: A theory of practical reasoning. Oxford: Clarendon.

31. Noggle, Robert. 2005. Autonomy and the paradox of selfcreation: Infinite regresses, finite selves, and the limits of authenticity. In Personal autonomy: New essays on personal autonomy and its role in contemporary moral philosophy, ed. James S. Taylor, 87-108. Cambridge u. a: Cambridge Univ. Press.

32. Waddell Ekstrom, Laura. 2005. Autonomy and personal integration. In Personal autonomy: New essays on personal autonomy and its role in contemporary moral philosophy, ed. James S. Taylor, 143-61. Cambridge u. a: Cambridge Univ. Press. 
33. Frankfurt, H.G. 2007. Identification and wholeheartedness. In The importance of what we care about: Philosophical essays, ed. H.G. Frankfurt, 159-76. Cambridge: Cambridge Univ. Press.

34. Kristjánsson, K. 2010. The self and its emotions. New York: Cambridge University Press.

35. Parfit, D. 1984. Reasons and persons. Oxford: Clarendon.

36. Olson Eric, T. 2003. Personal identity. In The Blackwell guide to philosophy of mind, 352-68. Malden: Blackwell.

37. Quante, M. 2007. Person. Berlin, New York: Walter de Gruyter.

38. Waddell Ekstrom, Laura. 1993. A coherence theory of autonomy. Philosophy and Phenomenological Research 53: 599-616.

39. Frankfurt, H.G. 2007. Freedom of the will and the concept of a person. In The importance of what we care about: Philosophical essays, ed. H.G. Frankfurt, 11-25. Cambridge: Cambridge Univ. Press.

40. Frankfurt, H.G. 2007. Rationality and the unthinkable. In The importance of what we care about: Philosophical essays, ed. H.G. Frankfurt, 177-90. Cambridge: Cambridge Univ. Press.

41. Frankfurt, H.G. 2003. Autonomy, necessity, and love. In Necessity, volition, and love, ed. H.G. Frankfurt, 129-41. Cambridge: Cambridge Univ. Press.

42. Bratman, M.E. 2000. Reflection, planning, and temporally extended agency. The Philosophical Review 109: 35-61.

43. Frankfurt Harry, G. 2007. The importance of what we care about: Philosophical essays. Cambridge: Cambridge Univ. Press.

44. Quante, M. 2002. Personales Leben und menschlicher Tod: Personale Identität als Prinzip der biomedizinischen Ethik. Suhrkamp: Frankfurt a.M.

45. MacIntyre, A.C. 1981. After virtue: A study in moral theory. Notre Dame: University of Notre Dame.

46. Ricoeur, P. 1992. Oneself as another. Chicago: University of Chicago Press.

47. Frankfurt, H.G. 2003. The faintest passion. In Necessity, volition, and love, ed. H.G. Frankfurt, 95-107. Cambridge: Cambridge Univ. Press.

48. Velleman, J.D. 2002. Identification and identity. In Contours of agency: Essays on themes from Harry Frankfurt, ed. S. Buss and L. Overton, 91-123. Cambridge, Mass: MIT Press.
49. Mele, A.R. 2001. Autonomous agents: From self-control to autonomy. Oxford: Oxford Univ. Press.

50. Taylor, C. 1992. The ethics of authenticity. Cambridge, London: Harvard University Press.

51. Elliot, C. 1998. The tyranny of happiness: ethics and cosmetic. In Enhancing human traits: ethical and social implications, ed. E. Parens, 177-88. Washington: Georgetown Univ. Press.

52. Ryckman, R.M. 2000. Theories of personality. Belmont, Ca.: Wadsworth.

53. Asendorpf, J.B. 2009. Persönlichkeits-psychologie-für Bachelor. Berlin, Heidelberg: Springer-Verlag Berlin Heidelberg.

54. Woods, S.P., J.D. Rippeth, E. Conover, C.L. Carey, T.D. Parsons, and A.I. Tröster. 2006. Statistical power of studies examining the cognitive effects of subthalamic nucleus deep brain stimulation in Parkinson's disease. The Clinical Neuropsychologist 20: 27-38.

55. Castelli, L., P. Perozzo, M. Zibetti, B. Crivelli, U. Morabito, M. Lanotte, et al. 2006. Chronic deep brain stimulation of the subthalamic nucleus for Parkinson's disease: effects on cognition, mood, anxiety and persona lity traits. European Neurology 55: 136-44.

56. Allport, G. W., and H. S. Odbert. 1936. Trait-names: a psycho-lexical study. Psychological Monographs 47.

57. McCrae, R.R., and P.T. Costa. 1987. Validation of the fivefactor model of personality across instruments and observers. Journal of Personality and Social Psychology 52: 81-90.

58. McCrae, R.R., and P.T. Costa. 1997. Personality trait structure as a human universal. American Psychologist 52: 509-16.

59. Livesley, W.J., and D.N. Jackson. 2002. Manual for the dimensional assessment of personality pathology. Port Huron: Sigma Press.

60. Cloninger, C. R. 1994. The temperament and character inventory (TCI): a guide to its development and use. St. Louis: Center for Psychobiology of Personality, Washington University.

61. Pukrop, R., I. Gentil, I. Steinbring, and E. Steinmeyer. 2001. Factorial structure of the german version of the dimensional assessment of personality pathology-basic questionnaire in clinical and nonclinical samples. Journal of Personality Disorders 15: 450-6.

62. Costa, P.T., and R.R. McCrae. 1992. NEO PI-R professional manual. Odessa, FL: Psychological Assessment Resources. 